\title{
Políticas Públicas em Educação Superior a Distância - Um estudo sobre a experiência do Consórcio Cederj
}

Georgia de Souza Assumpção ${ }^{a}$ Alexandre de Carvalho Castro ${ }^{b}$ Álvaro Chrispino ${ }^{c}$

\section{Resumo}

O presente trabalho tem por objetivo traçar um panorama geral sobre as Políticas Públicas em educação superior a distância, abordando as legislações mais relevantes que tratam de sua regulamentação, principais características, aspectos gerais da modalidade. Retrata-se, de modo particular, a experiência do Consórcio Cederj/Fundação Cecierj, um dos projetos pioneiros de educação a distância implementados no País. A partir dos estudos realizados ficou esclarecido que a EAD se mostra como uma ferramenta importante no processo de Políticas Públicas para ampliação da educação superior no país. Concluímos que o Consórcio Cederj pode ser considerado um caso de sucesso em educação a distância e, em que pesem limitações, está contribuindo de forma positiva para a expansão da educação superior no estado do Rio de Janeiro e, consequentemente, para uma ampliação da inclusão social no país.

Palavras-chave: Educação superior; Políticas Públicas; Educação a Distância; Cederj

\section{Introdução}

A educação superior está fortemente ligada ao desenvolvimento econômico e social do País, tanto em relação à formação de recursos humanos altamente qualificados, quanto em função da produção científica. Consequentemente, no âmbito de políticas públicas voltadas à educação (BRASIL, 2007a), é possível

\footnotetext{
a Instituto Brasileiro de Geografia e Estatística. Rio de Janeiro, Rio de Janeiro, Brasil.

b Centro Federal de Educação Tecnológica Celso Suckow da Fonseca. Rio de Janeiro, Rio de Janeiro, Brasil.

c Centro Federal de Educação Tecnológica Celso Suckow da Fonseca. Rio de Janeiro, Rio de Janeiro, Brasil.
} 
identificar uma série de medidas que visam à ampliação e à democratização do acesso ao ensino.

De fato, desde a década de 1990, uma das principais medidas adotadas para ampliar e democratizar o acesso à educação superior tem sido o incentivo à implementação da Educação a Distância (EAD), dinâmica que ocorre em função de iniciativas variadas, em nível federal, estadual e, eventualmente, municipal. O ponto de interesse desse amplo cenário para este artigo é que, dentro do conjunto geral dessas ações voltadas para a EAD, algumas têm sido consideradas como exemplares, como ocorre no caso, por exemplo, da experiência do Consórcio Cederj, um dos projetos implementados no País com expressivo sucesso (COSTA, 2007).

O Cederj é um consórcio formado por universidades públicas do estado do Rio de Janeiro em parceria com a Secretaria de Estado de Ciência e Tecnologia do Estado do Rio de Janeiro e o Sistema Universidade Aberta do Brasil, por intermédio da Fundação Cecierj, com o objetivo de oferecer cursos de graduação a distância, na modalidade semipresencial, para todo o estado.

Atualmente, o consórcio é composto por oito instituições públicas de ensino superior: Cefet-RJ (Centro Federal de Educação Tecnológica Celso Suckow da Fonseca), IFF (Instituto Federal de Educação, Ciência e Tecnologia Fluminense), UENF (Universidade Estadual do Norte Fluminense Darcy Ribeiro), UERJ (Universidade do Estado do Rio de Janeiro), UFF (Universidade Federal Fluminense), UFRJ (Universidade Federal do Rio de Janeiro), UFRRJ (Universidade Federal Rural do Rio de Janeiro) e Unirio (Universidade Federal do Estado do Rio de Janeiro).

Do ponto de vista histórico (HANSEN, 2004), a ideia da criação de um consórcio com tais características remonta ao projeto de Darcy Ribeiro para a UENF, porque, no estado do Rio de Janeiro, as universidades públicas, na época, estavam todas localizadas no eixo Rio-Niterói. A ideia era fazer da UENF um modelo de Educação a distância que proporcionasse aos jovens do interior a oportunidade de fazerem cursos superiores, sem deixarem suas cidades de origem (FREIRE, 2013).

A ideia de um consórcio no Rio de Janeiro, que oferecesse oportunidades de ensino no interior do estado, começou a ser posta em prática por Wanderley de Souza, reitor da UENF, que, em 1998, na condição de Secretário de Ciência e Tecnologia do estado, convocou as universidades públicas do Rio de Janeiro a se unirem para montar uma universidade a distância, para "abrir suas portas em direção ao interior" (HANSEN, 2004). Nesse mesmo ano de 1998, foi também criada a Superintendência de Educação a Distância da Secretaria de Ciência e 
Tecnologia, tendo sido convidado para presidi-la Carlos Bielschowsky, então professor titular do Instituto de Química da UFRJ. Essa superintendência tinha a missão de articular as universidades públicas do Rio de Janeiro para o oferecimento de cursos de graduação a distância no interior do estado.

O consórcio começou a ser elaborado em 1999, por meio de documento gerado por comissão formada por membros de cada universidade juntamente com a Secretaria de Estado de Ciência e Tecnologia. Então, foi efetivado, no ano de 2000 (HANSEN, 2004), o Consórcio Cederj, formado por seis universidades públicas do Rio de Janeiro (UERJ, UFRJ, UFF, Unirio, UENF e UFRRJ).

O Cederj foi coordenado por Carlos Bielschowsky e, nesse início, o governo do estado era responsável pelo financiamento e operacionalização das atividades do consórcio, ficando as universidades com as responsabilidades acadêmicas e os municípios com toda a estrutura dos polos de apoio presencial (FREIRE, 2013). No entanto, com a criação da UAB em 2005, uma importante mudança na estrutura do Consórcio ocorreu. O financiamento, que até então era provido pelo governo do estado e pelos Municípios, passou a contar, também, com o apoio do Governo Federal. Foi através dos editais lançados pela UAB que as instituições públicas de Ensino Superior que ofereciam cursos a distância, ou tinham projetos para fazê-lo, poderiam concorrer a aportes financeiros para desenvolver seus cursos e polos. Já no primeiro edital da UAB, o Cederj teve seu projeto aprovado, juntamente com seus polos. A partir de então, algumas despesas, como pagamento de bolsas e aquisição de alguns materiais passaram a ser realizados pelo Governo Federal, via UAB (FREIRE, 2013).

A participação das demais instituições de Ensino Superior (IES), Cefet-RJ e IFF, no consórcio Cederj ocorreu apenas após alguns anos de sua criação. O Cefet-RJ, na oferta de cursos em nível de graduação, tornou-se participante a partir da deliberação do Conselho Superior da Fundação Cecierj/Consórcio Cederj ocorrida em 29 de novembro de 2010. O IFF, a partir de deliberação do mesmo Conselho, passou a integrar o Consórcio no ano de 2013, totalizando, assim, as oito instituições públicas de ensino.

Diante desse quadro geral, o presente trabalho tem por objetivo analisar o Consórcio Cederj em sua relação com as Políticas Públicas em educação superior a distância. A metodologia empregada, de viés eminentemente qualitativo, constituiu um estudo exploratório-descritivo na modalidade de análise documental, tendo sido analisados documentos e legislações relativos ao estabelecimento e expansão da educação a distância, como uma política pública, no Consórcio Cederj. 


\section{Políticas Públicas em educação superior a distância}

A expressão terminológica "Políticas Públicas" tem forte caráter polissêmico (CHRISPINO, 2016) e seu sentido poderá ser tão diverso quanto os valores, ideologias e contextos daquele que as formula. Assim sendo, como um metaconceito, pode-se entender as Políticas Públicas em termos de ações intencionais de governo a fim de atender às necessidades da coletividade.

Em que pese tal pluralidade, vale lembrar que o campo da Educação foi um dos pioneiros na oferta de bens e serviços como objeto de política pública (CASTRO, 2011), ressalva importante porque, neste artigo, o foco estará restrito às Políticas Públicas para EAD, no Cederj.

\subsection{Incentivo para a EAD}

O principal marco jurídico da Educação a Distância no Brasil foi a promulgação da Lei de Diretrizes e Bases da Educação Nacional (LDB) - a Lei no 9.394 de 20 de dezembro de 1996 (BRASIL, 1996). Realmente, a LDB/96 fez parte de um conjunto de políticas públicas voltadas a estabelecer as diretrizes e bases da educação nacional, sua finalidade, organização, administração, níveis e modalidades, e a partir dela, o sistema educacional do país passou a ser organizado em dois níveis - Educação Básica (compreendendo a educação infantil, o ensino fundamental e o ensino médio) e Educação Superior (onde se têm as graduações e pós-graduações lato sensu e stricto sensu).

Em se tratando de educação a distância, foi em seu artigo 80 que a LDB/96 prescreveu que o Poder Público incentivaria o desenvolvimento e a veiculação de programas de ensino a distância, em todos os níveis e modalidades de ensino, e de educação continuada (BRASIL, 1996). Mas outros desenvolvimentos não tardariam a acontecer.

Em 1998, objetivando regulamentar o artigo 80 da LDB, o Executivo Federal baixou, em 10 de fevereiro, o Decreto $n^{0} 2.494$ (BRASIL, 1998a), vindo a ser modificado em 27 de abril do mesmo ano pelo Decreto $\mathrm{n}^{\circ} 2.561$ (BRASIL, 1998b). Esses decretos serviram de apoio para os primeiros credenciamentos de cursos superiores de graduação a distância, embora parecessem ainda muito tímidos.

O Plano Nacional de Educação (PNE), abordado na LDB/96, só foi sancionado em 2001, pela Lei ${ }^{\circ} 10.172$ (BRASIL, 2001). Ele foi assentado sobre três ideias chaves: a educação como direito de todos; a educação como fator de desenvolvimento social e econômico do país; e a educação como instrumento de 
combate à pobreza e de inclusão social. Para o Ensino Superior, suas principais premissas foram: fornecer, até o final da década, a oferta da educação superior para, pelo menos, $30 \%$ dos jovens entre 18 e 24 anos; ampliar a oferta do ensino público de modo a assegurar uma proporção de, pelo menos, $40 \%$ do total das vagas e estabelecer um amplo sistema de educação a distância (BRASIL, 2001).

É possível ver que no PNE, era reiterada a importância da EAD nas políticas de educação e foram estabelecidas diretrizes, objetivos e metas para a sua implantação. Para atender às demandas criadas na área, o plano deu ênfase à política de EAD para a formação de professores, propondo, entre seus objetivos, o aumento da oferta de Cursos de Pedagogia EAD e o apoio financeiro à pesquisa sobre EAD (BRASIL, 2001).

O PNE, contudo, implicou investimentos financeiros que não foram provisionados (COSTA, BARBOSA; GOTO, 2011). Isso fez com que fosse necessário estudar mais profundamente uma reconfiguração do ensino superior no País, embasandose em um documento intitulado Plano de Desenvolvimento da Educação (PDE).

Em 2005, portanto, nove anos depois da LDB/96 tratar da EAD em seu artigo 80, os Decretos $\mathrm{n}^{\circ} 2.494$ e $\mathrm{n}^{\mathrm{o}} 2.561$ foram revogados por um novo Decreto - o de $\mathrm{n}^{\circ} 5.622$ (BRASIL, 2005a). Assim, é possível dizer que foram necessários nove anos para se ter uma efetiva regulamentação da EAD no País.

Já em 2007, no PDE, o Ministério da Educação (MEC) observou que a educação superior devia ser analisada por meio dos seguintes princípios que se complementam: expansão da oferta de vagas; garantia de qualidade; promoção de inclusão social pela educação; distribuição territorial e desenvolvimento econômico e social (BRASIL, 2007a). O PDE visou a atender com qualidade a essa demanda de expansão, criando novos programas e aproveitando-se dos já existentes. Em relação à educação superior a distância, foi realizado um incremento por meio da Universidade Aberta do Brasil (UAB), com a criação de dezenas de polos em todo o país (BRASIL ${ }^{1}$ apud COSTA; COSTA; MELO, 2011).

Em 2014, com algum atraso, já que o I PNE era válido no período 2001-2011, foi aprovado o II PNE, também com vigência por dez anos. Nele, uma das metas, a de número 12, prevê uma elevação da taxa de matrícula na educação superior, objetivando-se assegurar, ao menos, $40 \%$ das novas matrículas no segmento público. A modalidade de educação a distância não foi citada de forma explícita, mas a

BRASIL. O Plano de Desenvolvimento da Educação completa 3 anos. Brasília, DF: MEC, 2010. Disponível em: $<$ http://pde3anos.mec.gov.br/>. 
estratégia de número 12.2 fez alusão à ampliação da oferta de vagas por meio da expansão e interiorização da rede federal de educação superior e do sistema UAB. Para alguns estudiosos da temática, essa meta 12 do II PNE parece refletir uma tentativa de diminuir o desequilíbrio das ofertas de cursos entre entidades privadas e públicas, porque, os elevados níveis de privatização da educação superior, no Brasil, se apresentam como um dos principais gargalos nas definições de políticas públicas para a educação superior brasileira (MATIAS-PEREIRA, 2008).

\subsection{Dificuldades para a EAD}

Em suma, a partir da década de 1990, ocorreram iniciativas no campo das políticas públicas de educação para melhorar o desempenho da educação nacional, e foram apresentadas propostas de mudança, desde a educação fundamental até a superior, sendo que, no que diz respeito à educação superior, a necessidade de reformulação estava explícita no I PNE. Essa lei propunha a elevação da taxa de escolarização da população de 19 a 24 anos para $30 \%$ num período de 10 anos, o que resultaria em mais 3,2 milhões de estudantes matriculados, dinâmica que induziria aumento de procura pelo ensino superior (SARAIVA; NUNES, 2011).

De fato, nos últimos anos, foi possível ver sinais de crescimento do ensino superior no Brasil, um processo que ainda necessita de muitos investimentos e melhorias. Os dados do último censo divulgados pelo INEP, no ano de 2013, mostram que o país ampliou o número de cursos e instituições, possibilitando mais acesso da sociedade à educação. No período 2012-2013, o número de matrículas em cursos de graduação cresceu $3,8 \%$, sendo que as IES privadas têm uma participação de $74 \%$ no total de matrículas de graduação. Nesse mesmo período, a matrícula cresceu 3,9\% nos cursos presenciais e 3,6\% nos cursos a distância. Ou seja, em 2013, os cursos a distância já contavam com uma participação superior a 15\% nas matrículas de graduação. (BRASIL, 2015), o que permite constatar que o oferecimento de cursos superiores na modalidade a distância é uma das políticas públicas que viabilizaram o aumento do número de matrículas e conclusões em cursos de graduação.

Entretanto, a implementação de políticas em educação a distância historicamente esbarrou em uma série de problemas estruturais, principalmente nas universidades públicas. As dificuldades eram diversas, como a falta de pessoal qualificado e de financiamento específico para EAD. Desse cenário de demandas e carências, emergiram soluções circunstanciais, onde o consorciamento de instituições para o oferecimento de tais cursos foi, então, uma das estratégias adotadas para o enfrentamento das dificuldades encontradas (FREIRE, 2013). 


\subsection{O consórcio público}

A figura dos consórcios públicos surgiu com a Emenda Constitucional 19/1998, que estabeleceu que a União, os Estados, o Distrito Federal e os Municípios disciplinariam, por meio de lei, os consórcios públicos e os convênios de cooperação entre os entes federados, com a finalidade de executar a gestão associada de serviços públicos (BRASIL, 1998c).

A Lei dos Consórcios Públicos (Lei n ${ }^{\circ}$ 11.107) (BRASIL, 2005b), entretanto, foi promulgada somente em 2005, e regulamentada através do Decreto ${ }^{\circ} 6.017 / 2007$ (BRASIL, 2007b), quase uma década depois da emenda que definiu consórcio público como:

[...] pessoa jurídica formada exclusivamente por entes da Federação, na forma da Lei no 11.107, de 2005, para estabelecer relações de cooperação federativa, inclusive a realização de objetivos de interesse comum, constituída como associação pública, com personalidade jurídica de direito público e natureza autárquica, ou como pessoa jurídica de direito privado sem fins econômicos (BRASIL, 2007b).

Essa forma de organização atendeu a um princípio da administração pública: o princípio da coordenação (FREIRE, 2013). Esse princípio é assegurado pelo Decreto-lei no 200, de 1967, ainda em vigência no Brasil. Para Meirelles (1998):

O princípio da coordenação visa entrosar as atividades da Administração, de modo a evitar a duplicidade de atuação, a dispersão de recursos, a divergência de soluções e outros males característicos da burocracia. Coordenar é, portanto, harmonizar todas as atividades da Administração (p. 607).

O que é importante ressaltar é que, através desses consórcios, a soma de esforços e estruturas acabou por tornar possível a implementação de políticas de EAD que, isoladamente, dificilmente uma Instituição Pública de Ensino Superior (IPES) poderia realizar (VALLADARES et al., 2007). E, por conta disso, antes mesmo da regulamentação dos consórcios públicos, algumas instituições valeram-se dessa modalidade de associação para a criação e o oferecimento de cursos, que foram iniciativas pioneiras no País. Podem ser citadas a UniRede, consórcio também denominado Universidade Virtual Pública, criado em 1999; o Projeto Veredas, que foi um curso de formação superior a distância, proposto pela Secretaria de Educação de Minas Gerais, realizado em parceria com 18 IES daquele estado, entre os anos de 2002 e 2005; e o próprio Consórcio Cederj, constituído no ano 
de 2000. Todavia, o caso do Cederj, particularmente, representou uma maior complexidade, por imbricar institucionalmente um consórcio e uma fundação.

\section{O Consórcio Cederj, a Fundação Cecierj e o Sistema Universidade Aberta do Brasil}

No campo das políticas públicas do país, há vários estímulos que visam a promover um crescente envolvimento das instituições públicas de educação superior com a EAD (MATIAS-PEREIRA, 2008). No caso especificamente do Cederj, o fundamental é perceber que tais políticas públicas de educação a distância mantêm significativa interface com o Cecierj e a UAB.

\subsection{O Consórcio Cederj e a Fundação Cecierj}

A fim de se situar adequadamente o âmbito de ação do consórcio Cederj, mostra-se importante compreender um pouco da Fundação Cecierj, pois o Cederj está vinculado a essa Fundação que, por sua vez, está ligada à Secretaria de Estado de Ciência, Tecnologia e Inovação do Estado do Rio de Janeiro.

A gestão do Cederj é realizada pelo Núcleo Gestor do Consórcio. Os principais órgãos de decisão do Cederj, em ordem hierárquica, são o Colegiado de Coordenadores de Curso, integrado pelos coordenadores dos cursos, o Conselho de Estratégias Acadêmicas e o Conselho Superior, estes integrados, respectivamente, pelos pró-reitores acadêmicos e pelos reitores das universidades consorciadas. Todos esses órgãos são de deliberação colegiada e presididos pelo presidente da Fundação Cecierj (COSTA, 2007).

A Fundação Centro de Ciências e Educação Superior a Distância do Estado do Rio de Janeiro - Fundação Cecierj - teve sua origem na década de 1960 (VIANNA; ENNE, 2012). Sua história remonta ao período quando, em 30 de novembro de 1965, foi criado o Centro de Ciências da Guanabara (Cecigua), órgão integrante da estrutura orgânica da Secretaria de Estado de Ciência e Tecnologia - Sectec, do extinto estado da Guanabara. Posteriormente, após a fusão dos estados da Guanabara e do Rio de Janeiro, o Cecigua foi transformado em Centro de Ciências do Estado do Rio de Janeiro, uma autarquia, com personalidade jurídica de direito público, a partir da Lei n ${ }^{\circ} 1.637$, de 29 de março de 1990 (RIO DE JANEIRO, 1990). Contudo, através da Lei Complementar $\mathrm{n}^{\circ}$ 103, de 18 de março de 2002 (RIO DE JANEIRO, 2002), deixou de ser uma autarquia, passando à situação atual de fundação, com personalidade jurídica de direito público, ficando integrada à Administração Indireta e vinculada à Secretaria de Estado de Ciência e Tecnologia, do Estado do Rio de Janeiro. 
Em que pese tais mudanças organizacionais, o Cecierj, ainda que sob diferentes formatos, em todos esses anos atuou principalmente no atendimento às necessidades formativas dos professores, desenvolvendo programas de educação continuada para professores, e oferecendo cursos presenciais relacionados ao ensino de física, química, matemática, biologia e geologia.

A Fundação Cecierj desenvolve projetos nas áreas de educação superior a distância e divulgação científica, atingindo diretamente os residentes de todos os 92 municípios do estado do Rio de Janeiro. Além de oferecer cursos de graduação por intermédio do Consórcio Cederj, mantém o projeto de formação continuada de professores da educação básica, com a oferta de cursos modulares em diversas áreas e Projetos de Divulgação Científica.

Por meio de sua diretoria de Extensão, a Fundação Cecierj é responsável pela coordenação de duas revistas virtuais voltadas para o ensino e a pesquisa. São elas a Revista da Educação Pública, um espaço de interação entre os professores e educadores, e a Revista EAD em Foco, uma revista científica em educação a distância.

Frente a tal conjunto de ações, é fundamental destacar, para a adequada compreensão do argumento aqui desenvolvido, que há uma forte relação institucional, sobretudo, porque a Fundação Cecierj é responsável por toda a estrutura administrativa dos cursos oferecidos pelo consórcio Cederj; o que inclui aspectos da administração escolar (organização do processo de seleção e avaliação presencial dos alunos), do acompanhamento tutorial (seleção, capacitação e avaliação dos tutores presenciais), da estruturação didática (manutenção dos cursos no site, através da plataforma na internet, acompanhamento da produção de material didático e sua consequente distribuição entre os alunos), e da avaliação institucional do próprio Cederj. (FREIRE, 2013)

Ainda sobre a Fundação Cecierj e o Consórcio Cederj, é preciso chamar atenção para algumas fragilidades identificadas. Tem-se, por exemplo, a precarização do trabalho docente ocorrido na contratação dos tutores que atuam nos cursos do Cederj (MANCEBO;VALE, 2014; CASTRO, 2016), uma vez que eles não têm vínculo efetivo com a Fundação Cecierj (nem com as IES envolvidas), sendo apenas bolsistas da área de pesquisa. $\mathrm{O}$ quadro pode ser considerado ainda mais grave porque os valores das bolsas são considerados baixos pelos próprios tutores, que também não têm direito a benefícios de alimentação, saúde, transporte nem décimo terceiro salário. De fato, esses tutores formam um grupo profissional que carece de perfil profissiográfico, já que - conquanto se considerem realizando uma atuação docente - não são reconhecidos nem remunerados adequadamente (HACKMAYER; BOHADANA, 2014). 
Nesse cenário, é igualmente importante ressaltar que o processo seletivo desses profissionais é realizado através de análise de currículo, ocasião onde a titulação acadêmica e a experiência profissional são pontuadas e consideradas muito relevantes (FUNDAÇÃO CENTRO DE CIÊNCIAS E EDUCAÇÃO SUPERIOR A DISTÂNCIA DO ESTADO DO RIO DE JANEIRO, 2016), o que implica dizer que, consequentemente, muitos tutores são especialistas, mestres e doutores nas áreas dos cursos onde atuam. Tais situações, enfim, ensejaram a criação, no início do ano de 2016, da Associação dos Docentes e Profissionais do Ensino a Distância do Rio de Janeiro (Adopead/RJ Seção Sindical do Andes-SN) e vários movimentos de paralização das atividades de tutoria acabaram por ocorrer no ano de 2016, por todo o estado do Rio de Janeiro, em função da falta de pagamento das bolsas.

\subsection{O Consórcio Cederj e o Projeto UAB}

Há, além da Fundação Cecierj, uma outra importante interface do Cederj: a UAB (COSTA, 2007). Isso porque o consórcio Cederj foi um dos quatro projetos considerados como seminais para o estabelecimento do Sistema UAB, juntamente com o curso de Pedagogia da UFMT (1995); o projeto Veredas Minas Gerais (2002); e o projeto piloto do curso de administração do Banco do Brasil (2006). De fato, a UAB foi um projeto criado pelo Ministério da Educação e a Associação dos Dirigentes das Instituições Federais de Ensino (Andifes), no âmbito do Fórum das Estatais pela Educação, no ano de 2005. Tinha como objetivo a oferta de cursos e programas de educação superior a distância, em parceria com Universidades Públicas, por meio de consórcios com municípios e estados da Federação. O projeto compunha o conjunto de políticas públicas desenvolvidas para a área da educação, e era voltado especialmente para a expansão da educação superior, a fim de ampliá-la e interiorizá-la, preocupando-se com a qualidade e gratuidade (MOTA, 2007).

O Decreto $\mathrm{n}^{0} 5.800$, de 8 de junho de 2006 (BRASIL, 2006a), é que dispõe sobre a criação do Sistema UAB, estando de acordo com o disposto nos artigos 80 e 81 da LDB/96, no PNE de 2001, na Lei no 11.273/2006 (BRASIL, 2006b) e no Decreto $\mathrm{n}^{\circ}$ 5.622/2005 (BRASIL, 2005a). Os dois primeiros objetivos do Sistema UAB são oferecer cursos para professores da educação básica e para os dirigentes, gestores e trabalhadores em educação básica dos Estados, do Distrito Federal e dos Municípios. Observa-se assim, uma preocupação com a formação de profissionais em serviço ligados à educação básica. $O$ terceiro objetivo encontrado no Decreto ${ }^{\circ} 5.800$ (BRASIL, 2006a) é oferecer cursos superiores nas diferentes áreas do conhecimento. 
O modelo da Universidade Aberta do Brasil, contudo, é um modelo em construção, motivado por outras organizações internacionais, como, por exemplo, a experiência espanhola da Universidad Nacional de Educación a Distancia e The Open University, do Reino Unido (MATIAS-PEREIRA, 2008). De qualquer forma, pode-se dizer que o sistema UAB não configura uma unidade de ensino, nem possui uma estrutura física (SEMBAY, 2009). Ou seja, não se trata de uma nova universidade, mas de um programa que congrega o conjunto das atividades de algumas IES.

Do ponto de vista das Políticas Públicas, portanto, a UAB pode ser entendida como um órgão do MEC que articula instituições públicas (como universidades e Cefets), responsáveis pela oferta de cursos superiores na modalidade a distância (COSTA, 2007). Sendo assim, funciona em parceria com prefeituras e instituições de ensino que, de forma autônoma, oferecem esses cursos e cedem as estruturas físicas necessárias para a sua implantação.

Os primeiros cursos executados no âmbito do Sistema UAB resultaram da publicação de editais. O primeiro edital, de dezembro de 2005, permitiu a concretização do Sistema UAB, por meio da seleção para integração e articulação das propostas de cursos, apresentadas exclusivamente por instituições federais de ensino superior, e as propostas de polos de apoio presencial, apresentadas por estados e municípios. O segundo edital, de outubro de 2006 , diferiu da primeira experiência por permitir a participação de todas as instituições públicas, inclusive as estaduais e municipais. Em 2007, o sistema UAB repassou recursos às instituições de ensino superior para a ampliação do acervo bibliográfico dos polos de apoio presencial.

O Catálogo UAB traz em sua seção introdutória, a informação de que havia previsão do estabelecimento de 1.000 polos até o ano de 2010, estrategicamente distribuídos no território nacional. Até 2013, pretendia-se uma ampliação da rede de cooperação para alcançar a totalidade das IPES brasileiras e atender a 800 mil alunos/ano. Na seção dedicada à região Sudeste, tem-se acesso a números que indicavam uma tendência de crescimento contínuo de vagas ofertadas entre os anos de 2007 e 2009, na maioria dos polos então ativos no estado do Rio de Janeiro, conforme pode ser visto no Quadro 1 (CAPES/UAB).

Quadro 1. Número de polos e vagas no estado do Rio de Janeiro.

\begin{tabular}{|l|c|c|c|c|}
\hline $\begin{array}{l}\text { Número de polos no } \\
\text { estado do RJ }\end{array}$ & $\begin{array}{c}\text { Vagas em } \\
\mathbf{2 0 0 7}\end{array}$ & $\begin{array}{c}\text { Vagas em } \\
\mathbf{2 0 0 8}\end{array}$ & $\begin{array}{c}\text { Vagas em } \\
\mathbf{2 0 0 9}\end{array}$ & Vagas totais \\
\hline 31 & 3014 & 7472 & 9060 & 19546 \\
\hline
\end{tabular}

Fonte: Adaptado de Universidade Aberta do Brasil, 2015. 
Entre 2007 e julho de 2009, foram aprovados e instalados 557 polos de apoio presencial com 187.154 vagas criadas, em todo o território nacional. Em agosto de 2009, a UAB selecionou mais 163 novos polos, ampliando a rede para um total de 720 polos (CAPES/UAB).

No ano de 2015, o sistema de Consulta do sítio UAB/Capes aponta a existência de 643 polos, 105 IPES associadas e 697 cursos oferecidos em todo Brasil, demonstrando números inferiores aos inicialmente planejados.

\section{A EAD no Cederj}

Estudos acadêmicos viabilizam, pelas análises efetuadas, a ordenação racional de ações, métodos e técnicas que permitam que se alcançasse os objetivos propostos pelas Políticas Públicas em educação, integrando os entes federativos na identificação de necessidade de forma a atender o interesse coletivo com os recursos existentes e disponíveis (CHRISPINO, 2016). Daí a relevância de estudos que relacionam a oferta de cursos com a demanda de capacitação profissional em dadas regiões, pois enseja o debate de como melhorar a qualificação da mão de obra local disponível para a indústria e a área de serviços.

Ora, a maioria das concentrações econômicas do estado do Rio de Janeiro não dispõe, em número suficiente, de centros de formação de mão de obra qualificada (SALGADO, 2015), e no que diz respeito ao Cederj, já se constatou que os polos localizados em municípios com alto IDH (Índice de Desenvolvimento Humano) e proximidade relativa de cursos presenciais têm desempenho ruim, no que se refere à utilização de recursos (ANDRADE; BRANDÃO, 2010). Além disso, a distribuição geográfica dos polos nem sempre corresponde a critérios técnicos, sendo mais dependente de critérios políticos (MELLO; FARIAS FILHO, 2010), havendo, inclusive, propostas a partir da Análise Envoltória de Dados (DEA), de localidades que reuniriam melhores características ambientais para um novo polo do Cederj, no caso do curso de Matemática (GOMES JUNIOR; MELLO; MELLO, 2008).

Assim, a partir de tais premissas é que serão analisadas as características específicas dos cursos do Cederj, de acordo com a dinâmica própria da EAD.

\subsection{Os polos Cederj/UAB}

Os polos de apoio presencial são unidades operacionais que têm por objetivo o desenvolvimento descentralizado de atividades pedagógicas e administrativas relativas aos cursos e programas ofertados a distância pelas IES no âmbito do 
Sistema UAB. São mantidos pelos municípios ou governos do estado, oferecendo infraestrutura física, tecnológica e pedagógica para o acompanhamento das atividades dos cursos a distância, pelos alunos (CAPES/UAB).

O polo Cederj, aprovado e mantido com auxílio de recursos da UAB, é uma referência física para que os alunos possam realizar atividades presenciais obrigatórias como aulas no laboratório, avaliações, tutoria presencial. Atualmente, são um total de 33 polos distribuídos pelo estado, sendo que o Polo Maracanã não vem oferecendo novas vagas em cursos. A cada semestre, o Cederj divulga a relação entre polos x cursos oferecidos, sendo possível notar uma ampliação das atividades nos últimos anos. O mapa de distribuição dos polos pelo estado do RJ é apresentado na Figura.

Todos os 92 municípios do estado do Rio de Janeiro apresentam alunos ativos no Cederj, sendo que os polos de apoio presencial estão localizados em 31 deles. Os cinco municípios com maior densidade de alunos no Consórcio (normalizados pelo número de habitantes) são os municípios de Itaocara, São Fidélis, Cantagalo, Cordeiro e São Sebastião do Alto. Nestes municípios, observou-se que havia mais que sete alunos ativos no Cederj para cada 1.000 habitantes, chegando a 8,25 alunos a cada 1.000 habitantes no município de Itaocara. Considerando-se a

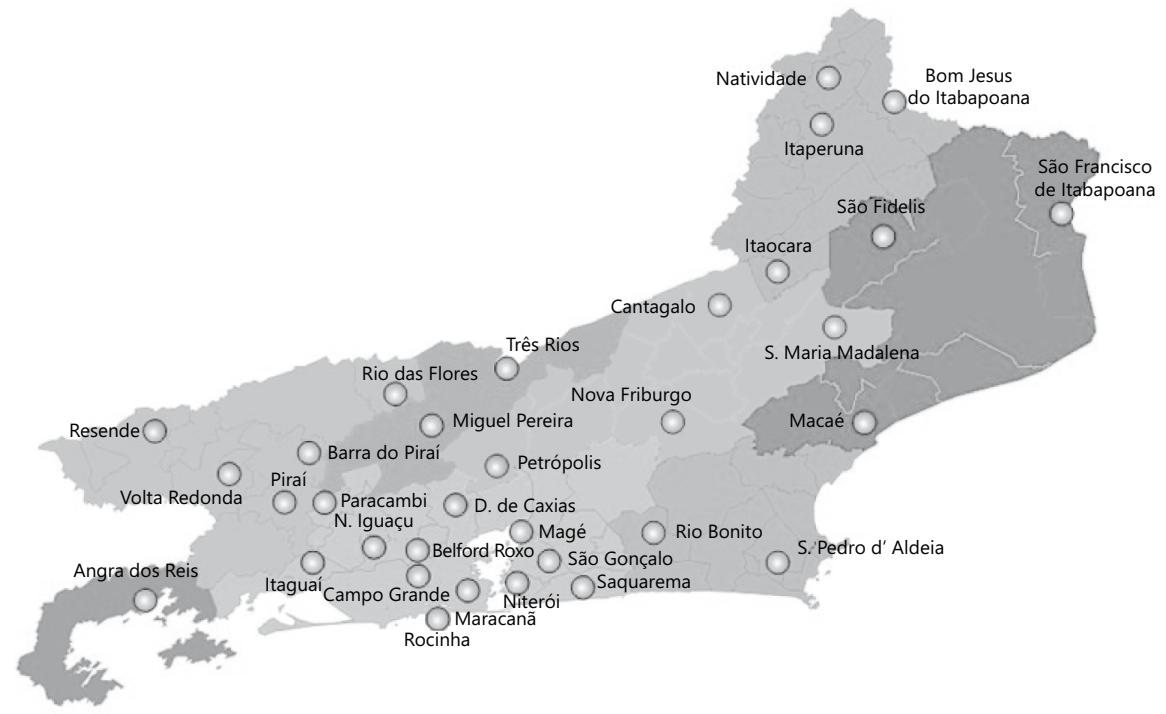

Fonte: Adaptado de Cederj (RIO DE JANEIRO, 2015).

Figura. Distribuição dos polos do Cederj. 
definição das mesorregiões geográficas ${ }^{2}$ do estado do Rio de Janeiro e analisando sob a ótica do número relativo de alunos, os maiores índices (IACMH) estão nas macrorregiões do Noroeste Fluminense (3,99/1.000 habitantes), do Sul Fluminense $(3,82 / 1.000$ habitantes) e do Centro Fluminense (3,77/1.000 habitantes), revelando uma prioridade de atuação do Cederj nas regiões distantes da capital e de Campos dos Goytacazes. (CASSIANO et al., 2016).

\subsection{Forma de ingresso nos cursos}

O ingresso aos cursos de graduação a distância oferecidos pelas IES que integram o Consórcio Cederj é realizado por meio do Vestibular Cederj, que acontece duas vezes por ano, ou pelo uso da nota obtida no último ENEM (Exame Nacional do Ensino Médio) realizado.

O consórcio Cederj adota o que podemos chamar de Políticas Compensatórias (isenção de taxa de inscrição e a adoção de cotas), que são políticas públicas utilizadas por sociedades muito desiguais, pois possuem caráter complementar e residual que permitem mitigar os efeitos da adversidade econômica (CHRISPINO, 2016).

Para os candidatos que comprovem insuficiência de recursos financeiros, existe a possibilidade de obtenção de isenção de pagamento da taxa de inscrição do Vestibular. Para isso, antes do anúncio da inscrição do Vestibular, é aberta a inscrição para a solicitação de isenção do pagamento.

As IES que compõem o consórcio Cederj reservam percentuais de vagas (cotas) para candidatos, adotando critérios e cumprindo leis, de acordo com o ente da federação a que estão vinculadas.

As universidades estaduais (UENF e UERJ), em cumprimento à Lei Estadual $\mathrm{n}^{\mathrm{o}}$ 5.346/2008 (RIO DE JANEIRO, 2008), com vistas à redução de desigualdades étnicas, sociais e econômicas permite aos candidatos carentes (com renda per capita menor ou igual a $\mathrm{R} \$ 1.017,00)$ a possibilidade de concorrerem a vagas reservadas para: negros; indígenas; alunos da rede pública de ensino; pessoas portadoras de deficiência, nos termos da legislação em vigor; filhos de policiais civis e militares, bombeiros militares e inspetores de segurança e administração penitenciária, mortos ou incapacitados em razão do serviço.

As universidades federais (UFF, UFRJ, UFRRJ, Unirio) e o Cefet reservam um percentual de vagas para os candidatos que: sejam oriundos do ENEM do

2 Disponível em: <http://www.ceperj.rj.gov.br/ceep/info_territorios/divis_regional.html>. 
ano anterior; tenham renda per capita menor ou igual a um salário mínimo e meio; tenham cursado integralmente, com aprovação, todas as séries do Ensino Médio, ou equivalente, em estabelecimentos de ensino da rede pública brasileira; sejam negros/pardos ou pertencentes a povos indígenas. Essas IES agem de acordo com a distribuição dos percentuais estabelecidos no artigo $3^{\circ}$ da Lei ${ }^{\circ}$ 12.711/2012 (BRASIL, 2012a), regulamentada pelo Decreto $\mathrm{n}^{\mathrm{o}} 7.824 / 2012$ (BRASIL, 2012b) e pela Portaria Normativa do MEC $\mathrm{n}^{\mathrm{o}} 18$, de 11/10/2012 (BRASIL, 2012c).

\subsection{Cursos oferecidos}

No início de suas atividades, assim como outros consórcios surgidos a partir do final da década de 1990, o Cederj tomou ações para a formação docente, visando à formação inicial de professores em serviço, habilitando docentes da rede pública de ensino para o exercício do magistério. Com o tempo, o Cederj foi ampliando sua atuação para outros cursos além das licenciaturas, integrando à instituição cursos de Administração, Administração Pública, Turismo e outros. Com isso, também foram crescendo o número de alunos, de polos e de instituições participantes, como já identificado anteriormente.

A atual oferta de cursos e polos pode ser visualizada através do Quadro 2.

\subsection{Características pedagógicas dos cursos do Cederj}

Finalizando o panorama geral da experiência do consórcio Cederj, vale a pena ressaltar algumas características como a forma de avaliação, ambiente virtual de aprendizagem utilizado, calendário de cursos e a relação dos cursos disponibilizados por cada uma das IES participantes do consórcio.

Como já mencionado, a modalidade de ensino oferecida no Cederj é semipresencial. Nos polos espalhados pelo estado do Rio de Janeiro, são desenvolvidas atividades de laboratório, seminários e avaliações presenciais. Esse formato está de acordo com o Decreto $\mathrm{n}^{\circ}$ 5.622/2005 que, em seu artigo quarto, prevê que a avaliação do desempenho do estudante para fins de promoção, conclusão de estudos e obtenção de diplomas ou certificados deverá ser realizada através de exames presenciais (BRASIL, 2005a).

O Ambiente Virtual de Aprendizagem (AVA) pode ser entendido como um local virtual, onde são disponibilizadas ferramentas que permitem o acesso ao curso e a suas disciplinas, possibilitando também a interação entre alunos, tutores e coordenadores de curso. Na Plataforma Cederj, outra forma como o AVA é 
Quadro 2. Relação polos x cursos.

\begin{tabular}{|c|c|c|c|c|c|c|c|c|c|c|c|c|c|c|c|}
\hline \multirow[b]{2}{*}{ POLOS } & \multicolumn{15}{|c|}{ CURSOS OFERECIDOS } \\
\hline & 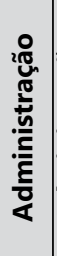 & 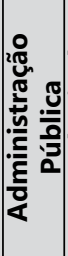 & 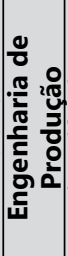 & 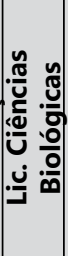 & 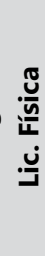 & 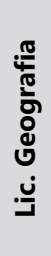 & 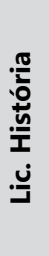 & 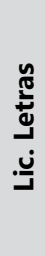 & 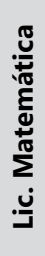 & 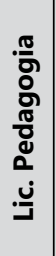 & 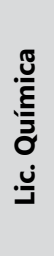 & 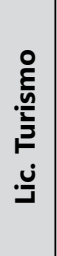 & 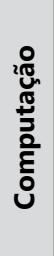 & 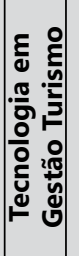 & 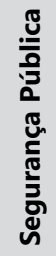 \\
\hline Angra dos Reis & $x$ & & $x$ & $x$ & $x$ & & & & $x$ & $x$ & $\mathrm{X}$ & $x$ & $\mathrm{X}$ & & $x$ \\
\hline Barra do Piraí & $x$ & & & & & $x$ & & & & $x$ & & & $x$ & & $x$ \\
\hline Belford Roxo & & $X$ & $x$ & & & & & & $x$ & $x$ & & & $\mathrm{X}$ & & $x$ \\
\hline $\begin{array}{l}\text { Bom Jesus } \\
\text { Itabapoana }\end{array}$ & & $\mathrm{X}$ & & $x$ & & & & & $x$ & $x$ & & & & & \\
\hline Campo Grande & & $x$ & & $x$ & $x$ & $x$ & & & $x$ & & & $x$ & & & $x$ \\
\hline Cantagalo & $\mathrm{X}$ & & $x$ & & & & $x$ & & $x$ & $x$ & & & $\mathrm{X}$ & & \\
\hline Duque de Caxias & & & & $x$ & $x$ & & $x$ & & & & & & $\mathrm{X}$ & $x$ & \\
\hline Itaguaí & & & & & & & & & & $x$ & & & $\mathrm{X}$ & & \\
\hline Itaocara & & $x$ & & $x$ & & & & & $x$ & $x$ & & & $\mathrm{X}$ & & \\
\hline Itaperuna & $x$ & & $x$ & $x$ & $x$ & & & $x$ & $x$ & $x$ & & & & & $x$ \\
\hline Macaé & $\mathrm{X}$ & & $x$ & $x$ & $x$ & & & & $x$ & $x$ & & & & & \\
\hline Magé & $\mathrm{X}$ & & & $x$ & & & & & $x$ & $\mathrm{X}$ & & $x$ & & & \\
\hline Miguel Pereira & & & & & & & $x$ & & $x$ & $x$ & & & & $x$ & \\
\hline Natividade & & & & & & $x$ & & & & $X$ & & & & & \\
\hline Niterói & & & & & & $x$ & & & & $x$ & & & $\mathrm{X}$ & $x$ & $x$ \\
\hline Nova Friburgo & & & & $x$ & & $x$ & & $x$ & & $\mathrm{X}$ & $x$ & & & & $x$ \\
\hline Nova Iguaçu & & $x$ & & $x$ & $x$ & & & $x$ & $x$ & $\mathrm{X}$ & $x$ & & $\mathrm{X}$ & $x$ & \\
\hline Paracambi & & $x$ & & $x$ & $x$ & & & $x$ & $x$ & $\mathrm{X}$ & $x$ & & & & \\
\hline Petrópolis & $\mathrm{X}$ & & & $x$ & & & & & $X$ & $X$ & & & & & $x$ \\
\hline Piraí & $x$ & & $x$ & $x$ & & & $x$ & $x$ & $x$ & $\mathrm{X}$ & $x$ & & $\mathrm{x}$ & & \\
\hline Resende & $\mathrm{X}$ & & $\mathrm{X}$ & $\mathrm{X}$ & & & $x$ & & $x$ & $x$ & & $x$ & & & $x$ \\
\hline Rio Bonito & & & & & & & & & $x$ & $x$ & & & $\mathrm{X}$ & & \\
\hline Rio das Flores & $\mathrm{X}$ & & & & & & & & & $x$ & & & $\mathrm{X}$ & & \\
\hline Rocinha & $x$ & & & & & & & & & $x$ & & & $\mathrm{x}$ & $x$ & \\
\hline $\begin{array}{l}\text { Santa Maria } \\
\text { Madalena }\end{array}$ & & & & & & & & & & $x$ & & & & & \\
\hline São Fidélis & $\mathrm{X}$ & & & $x$ & & & & & $x$ & $x$ & $x$ & & $\mathrm{x}$ & & \\
\hline $\begin{array}{l}\text { São Francisco de } \\
\text { Itabapoana }\end{array}$ & & & & $x$ & & & & $x$ & $x$ & $x$ & $x$ & & & & \\
\hline São Gonçalo & $x$ & & $x$ & $x$ & $x$ & & & & $x$ & & $x$ & $x$ & $\mathrm{X}$ & & $x$ \\
\hline $\begin{array}{l}\text { São Pedro da } \\
\text { Aldeia }\end{array}$ & & & & & & & & & $x$ & $x$ & & & & & \\
\hline Saquarema & $\mathrm{X}$ & & & & & & & & $x$ & $x$ & & $x$ & $\mathrm{X}$ & & \\
\hline Três Rios & & $x$ & & $x$ & $x$ & $x$ & & & $x$ & $x$ & & & $\mathrm{X}$ & & $x$ \\
\hline Volta Redonda & & $\mathrm{X}$ & & $x$ & $x$ & & & & $x$ & $X$ & & & $x$ & & \\
\hline
\end{tabular}

Fonte: Adaptado de Cederj (RIO DE JANEIRO, 2015). 
conhecido, estão disponíveis os materiais de estudo de cada uma das disciplinas do curso, as avaliações a distância, os cronogramas de atividades, as ferramentas de comunicação e outras ações específicas de cada disciplina. Ela é baseada no Moodle (Modular Object-Oriented Dynamic Learning Environment), um software livre amplamente utilizado em todo o mundo.

O Cederj adota um calendário único para todos os cursos, com todas as ações do semestre como avaliação a distância, avaliação presencial, seminários, férias. Esse calendário é diferente dos calendários acadêmicos das instituições participantes do consórcio.

A relação de cursos oferecidos por cada uma das IES associadas ao Cederj pode ser verificada através do Quadro 3, que auxilia na construção do panorama geral das atividades do Consórcio.

Quadro 3. Cursos oferecidos por Instituições de Ensino.

\begin{tabular}{|c|c|c|c|c|c|c|c|c|c|c|c|c|c|c|c|}
\hline \multirow[b]{2}{*}{ IES } & \multicolumn{15}{|c|}{ CURSOS OFERECIDOS } \\
\hline & 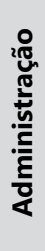 & 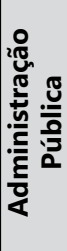 & 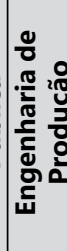 & 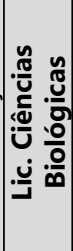 & 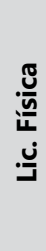 & 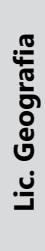 & 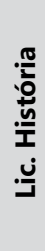 & 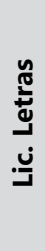 & 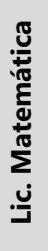 & 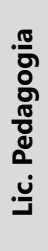 & 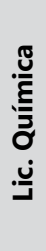 & 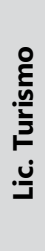 & 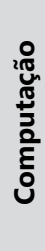 & 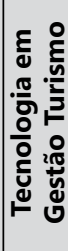 & 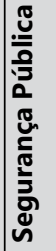 \\
\hline CEFET & & & $x$ & & & & & & & & & & & $x$ & \\
\hline UENF & & & & $x$ & & & & & & $x$ & $x$ & & & & \\
\hline UERJ & & & & $x$ & & $x$ & & & & $x$ & & & & & \\
\hline UFF & & $x$ & $x$ & & & & & $x$ & $x$ & & & & $x$ & & $x$ \\
\hline Unirio & & & & & & & $x$ & & $x$ & $x$ & & $x$ & & & \\
\hline UFRJ & & & & $x$ & $x$ & & & & & & $x$ & & & & \\
\hline UFRRJ & $x$ & & & & & & & & & & & $x$ & & & \\
\hline
\end{tabular}

Fonte: Adaptado de Cederj (RIO DE JANEIRO, 2015). 


\section{Considerações finais}

Há grande importância em pesquisas que possam servir para orientar as ações de políticas públicas em educação no Rio de Janeiro, a fim de distribuir oportunidades de estudo e absorção de mão de obra pelo interior do estado, hoje altamente concentrada na Região Metropolitana. Tendo em vista também que a formação superior, através dos cursos de graduação oferecidos pelo consórcio Cederj, mostra-se como uma alternativa viável para a ampliação da capacitação da população em regiões ainda não atendidas por outros centros de formação.

Por conta disso, o objetivo deste estudo foi analisar o Consórcio Cederj em sua relação com as Políticas Públicas em educação superior a distância, através do exame de documentos e legislações pertinentes. Assim sendo, foi traçado um panorama geral sobre as Políticas Públicas em educação superior a distância, enfocando com maiores detalhes a experiência do Consórcio Cederj. Foram abordadas as políticas públicas que ensejaram a formação do instrumento de consórcio público; apresentadas as principais políticas públicas para EAD no Brasil; avaliadas as relações implicadas na Fundação Cecierj e no Sistema UAB; e, do ponto de vista educacional, detalhada a dinâmica do consórcio Cederj.

Foi possível constatar que, no Brasil, houve uma expansão do número de cursos oferecidos e uma reordenação do campo da educação a distância por parte do poder público, o que criou condições para o crescimento acelerado do ensino superior nessa modalidade na última década. A EAD como uma política pública educacional baseou-se em argumentos de que essa modalidade pode contribuir para o crescimento econômico e a inclusão social.

Apesar desses avanços, considerou-se a necessidade de adotar uma visão crítica que permitisse identificar, além dos supostos benefícios propagados, as limitações e dificuldades associadas a essa modalidade educacional. Destaca-se esse ponto como relevante para aqueles interessados no estudo do tema, permitindo assim, uma visão mais ampla e um melhor entendimento do assunto.

Dentro dessa perspectiva crítica é que o estudo procurou analisar, oferecendo um panorama geral das políticas públicas para educação superior a distância, o Consórcio Cederj/Fundação Cecierj/UAB, abordando sua criação, ligação com outras iniciativas públicas, constituição, ampliação de cursos oferecidos e espaços atingidos. O que se verificou, em suma, é que, apesar de não ter havido um planejamento prévio para a criação, instituição de parcerias ou ampliação de número de alunos atendidos, é possível dizer ser o Consórcio Cederj/Fundação 
Cecierj/UAB uma experiência exitosa, já tendo completado mais de uma década de existência e atividades.

A contribuição desta pesquisa para o campo de estudos nessa área foi a de colaborar para o mapeamento estrutural do Consórcio, abrindo espaço para novas discussões sobre a eficiência do sistema como política de democratização do acesso à educação, principalmente dentro do estado do Rio de Janeiro. Contudo, é preciso ressaltar que o presente trabalho apresenta algumas limitações pelo fato de basear-se num levantamento de corte temporal, podendo sofrer alterações no curto ou médio prazo. Dessa forma, sugerem-se novas pesquisas para analisar, com maior frequência e acompanhamento, a questão do ensino superior, a modalidade de educação a distância e as políticas que sustentam e fomentam o crescimento de ambas. 


\title{
Public policies in Higher Distance Education - A study on the experience of Cederj Consortium
}

\begin{abstract}
This paper aims to outline an overview of the Public Policy in higher distance education, addressing the most important laws dealing with its regulation, main characteristics and general aspects of the modality. In particular, it is presented the experience of Cederj Consortium / Cecierj Foundation, one of the pioneering projects of distance education implemented in the country. From the study became clear that the distance education (EAD) is an important tool in the public policies process to increase the implementation of higher education in Brazil. The conclusion is that the Cederj Consortium can be considered a case of success in distance education, and in spite of limitations, is contributing positively to the expansion of higher education in the state of Rio de Janeiro and hence to an expansion of social inclusion in the country.
\end{abstract}

Keywords: Higher education. Public policies. Distance education. Cederj.

\section{Las políticas públicas en Educación Superior a Distancia - un estudio sobre la experiencia de Consorcio Cederj}

\section{Resumen}

Este trabajo tiene como objetivo elaborar una visión general de las Políticas Públicas en educación superior a distancia, frente a las legislaciones más importantes que se ocupan de su regulación, características principales, los aspectos generales de esta modalidad. Se retrata, en particular, la experiencia de Consorcio Cederj/Fundación Cecierj, uno de los pioneros en educación proyecta la distancia implementado en el País. A partir de los estudios realizados, quedó claro que la EAD se muestra como una herramienta importante en el proceso de Políticas Públicas para la expansión de la educación superior en el país. Llegamos a la conclusión de que el Consorcio Cederj puede considerarse un éxito en la educación a distancia, y a pesar de las limitaciones, está contribuyendo positivamente a la expansión de la educación superior en el Estado de Rio de Janeiro y, por tanto, a una expansión de la inclusión social en el país.

Palabras clave: Educación superior. Políticas públicas. Educación a distancia. Cederj. 


\section{Referências}

ANDRADE, F. V. S., BRANDÃO, L. C. Análise de Eficiência dos Pólos do CEDERJ. 2010. Trabalho de Conclusão de Curso (Graduação) - Faculdade de Engenharia de Produção, Universidade Federal Fluminense, Niterói, 2010.

BRASIL. Lei No 9.394, de 20 de dezembro de1996. Estabelece as diretrizes e bases da educação nacional. Diário Oficial da União da República Federativa do Brasil, Brasília, DF, 23 dez. 1996. Disponível em: <http://www.planalto. gov.br/ccivil_03/leis/19394.htm>. Acesso em: 16 dez. 2015.

. Decreto $\mathrm{N}^{\circ} 2.494$, de 10 de fevereiro de 1998. Regulamenta o art. 80 da Lei $\mathrm{n}^{\circ}$ 9.394, de 20 de dezembro de 1996, e dá outras providências. Diário Oficial da República Federativa do Brasil, Brasília, DF, 11 fev. 1998a. Disponível em: $<$ http://www2.camara.leg.br/legin/fed/decret/1998/decreto-2494-10-fevereiro1998-397980-publicacaooriginal-1-pe.html>. Acesso em: 17 dez. 2015.

. Decreto $\mathrm{N}^{\circ} 2.561$, de 27 de abril de 1998. Altera a redação dos arts. 11 e 12 do Decreto ${ }^{\circ} 2.494$, de 10 de fevereiro de 1998, que regulamenta o disposto no art. 80 da Lei n 9.394 de 20 de dezembro de 1996. Diário Oficial da República Federativa do Brasil, Brasília, DF, 28 abr. 1998b. Disponível em: $<$ http://www2.camara.leg.br/legin/fed/decret/1998/decreto-2561-27-abril-1998400794-publicacaooriginal-1-pe.html>. Acesso em: 15 dez. 2015 .

. Emenda Constitucional No 19, de 04 de junho de 1998. Modifica o regime e dispõe sobre princípios e normas da Administração Pública servidores e agentes políticos, controle de despesas e finanças públicas e custeio de atividades a cargo do Distrito Federal, e dá outras providências. Diário Oficial da República Federativa do Brasil, Brasília, DF, 05 jun. 1998c. Disponível em: $<$ http://www2.camara.leg.br/legin/fed/emecon/1998/emendaconstitucional-19-4junho-1998-372816-publicacaooriginal-1-pl.html>. Acesso em: 17 dez. 2015.

. Lei $\mathrm{N}^{\mathrm{o}} 10.172$, de 9 de janeiro de 2001. Aprova o Plano Nacional de Educação, e dá outras providências. Diário Oficial da República Federativa do Brasil, Brasília, 10 jan. 2001. Disponível em: <http://www.planalto.gov.br/ ccivil_03/leis/leis_2001/110172.htm>. Acesso em: 18 dez. 2015.

. Decreto $\mathrm{N}^{\mathrm{0}} 5.622$, de 19 de dezembro de 2005. Regulamenta o art. 80 da Lei ${ }^{\circ}$ 9.394, de 20 de dezembro de 1996, que estabelece as diretrizes e bases da educação nacional. Diário Oficial da República Federativa do Brasil, Brasília, DF, 20 dez. 2005a. Disponível em: <http:/www2.camara.leg.br/legin/fed/decret/2005/ decreto-5622-19-dezembro-2005-539654-publicacaooriginal-39018-pe.html $>$. Acesso em: 18 dez. 2015. 
BRASIL. Lei Federal No 11.107, de 6 abril de 2005. Dispõe sobre normas gerais de contratação de consórcios públicos e dá outras providências. Diário Oficial da República Federativa do Brasil, Brasília, DF, 07 abr. 2005b. Disponível em: <http://www.planalto.gov.br/ccivil_03/_ato2004-2006/2005/ lei/111107.htm>. Acesso em: 19 dez. 2015.

Decreto $N^{0} 5.800$, de 8 de junho de 2006. Dispõe sobre o Sistema Universidade Aberta do Brasil - UAB. Diário Oficial da República Federativa do Brasil, Brasília, DF, 9 jun. 2006a. Disponível em: <http://www.planalto. gov.br/ccivil_03/_ato2004-2006/2006/decreto/d5800.htm>. Acesso em: 19 dez. 2015.

. Lei $\mathrm{N}^{\mathrm{o}} 11.273$, de 06 de fevereiro de 2006. Autoriza a concessão de bolsas de estudo e de pesquisa a participantes de programas de formação inicial e continuada de professores para a educação básica. Diário Oficial da República Federativa do Brasil, Brasília, DF, 7 fev. 2006b. Disponível em: $<$ http://www.planalto.gov.br/ccivil_03/_ato2004-2006/2006/lei/111273.htm>. Acesso em: 15 dez. 2015.

. Ministério da Educação. O Plano de desenvolvimento da educação: razões, princípios e programas. Brasília, DF, 2007a.

. Decreto $N^{o} 6.017$, de 17 de janeiro de 2007. Regulamenta a Lei ${ }^{\circ}$ 11.107 , de 06 de abril de 2005, que dispõe sobre normas gerais de contratação de Consórcios Públicos. Diário Oficial da República Federativa do Brasil, Brasília, DF, 18 jan. 2007b. Disponível em: <http://www.planalto.gov.br/ ccivil_03/_ato2007-2010/2007/decreto/d6017.htm>. Acesso em: $18 \mathrm{dez} .2015$.

. Lei $\mathrm{N}^{\mathrm{o}} 12.711$, de 29 de agosto de 2012. Dispõe sobre o ingresso nas universidades federais e nas instituições federais de ensino técnico de nível médio e dá outras providências. Diário Oficial da República Federativa do Brasil, Brasília DF, 30 ago. 2012a. Disponível em <http://www2.camara. leg.br/legin/fed/lei/2012/lei-12711-29-agosto-2012-774113-normaatualizadapl.html>. Acesso em: 19 dez. 2015.

. Decreto $\mathrm{N}^{\mathrm{o}} 7.824$, de 11 de outubro de 2012. Regulamenta a Lei no 12.711, de 29 de agosto de 2012, que dispõe sobre o ingresso nas universidades federais e nas instituições federais de ensino técnico de nível médio. Diário Oficial da República Federativa do Brasil, Brasília, 15 out. 2012, retificado em 16 out. 2012b. Disponível em: http://www2. camara.leg.br/legin/fed/decret/2012/decreto-7824-11-outubro-2012-774384publicacaooriginal-137867-pe.html>. Acesso em: 19 dez. 2015. 
BRASIL. Portaria Normativa $\mathrm{N}^{\circ} 18$, de 11 de outubro de 2012. Dispõe sobre a implementação das reservas de vagas em instituições federais de ensino de que tratam a Lei ${ }^{\circ} 12.711$, de 29 de agosto de 2012, e o Decreto $n^{0} 7.824$, de 11 de outubro de 2012. Diário Oficial da União, Brasília, DF, 11 out. 2012c. Disponível em: < http://portal.mec.gov.br/cotas/docs/portaria_18.pdf $>$. Acesso em: 15 dez. 2015.

. Ministério da Educação. INEP. Resumo técnico: censo da educação superior. Brasília, 2015. Disponível em: <http://download.inep. gov.br/download/superior/censo/2013/resumo_tecnico_censo_educacao_ superior_2013.pdf>. Acesso em: 22 dez. 2015.

CASSIANO, K. M. et. al. Distribuição espacial dos polos regionais do Cederj: uma análise estatística. Ensaio: Avaliação e Políticas Públicas em Educação, v. 24, n.90, p. 82-108, 2016. doi: http://dx.doi.org/10.1590/S0104-40362016000100004

CASTRO, J. A. Política Social no Brasil: uma análise da ampliação do escopo, escala e gasto público Revista Brasileira de Monitoramento e Avaliação, n. 1, p. 66-95, jan./jun. 2011.

CASTRO, L. V. Professores "invisíveis"? Lutando por uma educação sem distância alguma. Revista Contemporânea de Educação, v. 11, n. 21, p. 82-97, jan/jul. de 2016. doi: http://dx.doi.org/10.20500/rce.v11i21.2228

CHRISPINO, A. Introdução ao estudo das políticas públicas. Rio de Janeiro: FGV/FAPERJ, 2016.

COSTA, D. M.; BARBOSA, F. V.; GOTO, M. M. M. O novo fenômeno da expansão da educação superior no Brasil. REUNA, Belo Horizonte, v.16, n.1, p 15-29, 2011.

COSTA, D. M.; COSTA, A. M.; MELO, P. A. A retroalimentação da educação superior no Brasil. Pretexto, Belo Horizonte, v. 12 n. 2 p. 61- 84, jun. 2011. Disponível em: <http://www.fumec.br/revistas/pretexto/article/view/666/573> Acesso em: 13 dez. 2017.

.FREIRE, D. L. Consórcio CEDERJ: as fragilidades de duas dimensões da organização. 2013. 133 f. Dissertação (Mestrado em Educação)-Universidade Federal do Rio de Janeiro, Rio de Janeiro, 2013. Disponível em: http://www. educacao.ufrj.br/ddjenane.pdf. Acesso em 13 dez. 2015. 


\section{FUNDAÇÃO CENTRO DE CIÊNCIAS E EDUCAÇÃO SUPERIOR A} DISTÂNCIA DO ESTADO DO RIO DE JANEIRO (CECIERJ). Consórcio CEDERJ. Seleção pública destinada à concessão de bolsas a tutores a distância para atuação nos cursos de graduação 2016.2 e formação de cadastro de reserva fundação: edital $\mathrm{n}^{\circ} 1 / 2016$. Rio de Janeiro: CECIERJ, 2016. Disponível em: <http://cederj.edu.br/fundacao/wp-content/ uploads/2016/06/EDITAL-TD-2016.pdf>. Acesso em: 25 out. 2016.

GOMES JÚNIOR, S. F.; MELLO, J. C. C. B. S.; MELLO, M. H. C. S. Utilização do método de Copeland para avaliação dos polos regionais do CEDERJ. Rio's International Journal on Sciences of Industrial and Systems Engineering and Management, v.2, p. 87-98. 2008. Disponível em: $<$ http:// www.rij.eng.uerj.br/scientific/2008/>. Acesso em: 18 dez. 2015.

HACKMAYER, M. B.; BOHADANA, E. Professor ou tutor: uma linha tênue na docência em EAD. RIED: Revista Iberoamericana de Educación a Distancia, v. 17, n. 2, p. 223-240, 2014. doi: https://doi.org/10.5944/ried.17.2.12685

HANSEN, K. Diretoria de Extensão promove encontro para educadores: educação para inclusão social é tema de encontro. Rio de Janeiro: Jornal Educação Pública, 2004. Disponível em: < http://www.educacaopublica.rj.gov. br/jornal/materias/0210.html>. Acesso em: 13 dez. 2015

MANCEBO, D.; VALE, A. A. Apontamentos preliminares sobre o trabalho docente no ensino a distância: o caso do Cederj. In: ROTHEN, J. C.; SILVA, E. P. (Org.). Políticas públicas para a educação superior. 1a ed. São Paulo: Xamã, 2014. p. 95-111.

MATIAS-PEREIRA, J. Políticas públicas de educação no Brasil: a utilização da EAD como instrumento de inclusão social. Journal of Technology Management \& Innovation, v. 3, n. 2, p. 44-55, 2008.

MEIRELLES, H. L. Direito Administrativo Brasileiro. 23. ed. atual. por Eurico de Andrade Azevedo, Délcio Balestero Aleixo e José Emmanuel Burle Filho. São Paulo: Malheiros, 1998.

MELLO, M. H. C. S.; FARIAS FILHO, J. R. Análise multicritério de localização de polos do CEDERJ - Resumo. In: Simpósio Brasileiro de Pesquisa Operacional - SBPO, 62, Bento Gonçalves. Resumos... Bento Gonçalves: UFSM, 2010. p. 3021-3022. 
MOTA, Ronaldo. Universidade Aberta do Brasil. ABRAEAD, 2007.

Disponível em: $<$ http://www.abraead.com.br/artigos_ronaldo.html $>$. Acesso em: 27 nov. 2015.

RIO DE JANEIRO (Estado). Lei No 1.637, de 29 de março de 1990.

Transforma em autarquia o Centro de Ciências da Secretaria de Estado de Ciência e Tecnologia. Diário Oficial do Estado do Rio de Janeiro. Rio de Janeiro, RJ, 29 mar. 1990. Disponível em: <https://gov-rj.jusbrasil.com.br/ legislacao/151400/lei-1637-90>. Acesso em: 15 dez. 2015.

. Lei $\mathrm{N}^{\mathrm{o}} 103$, de 18 de março de 2002. Transforma o Centro de Ciências do Estado do Rio de Janeiro na Fundação Centro de Ciências e Educação Superior à Distância do Estado do Rio de Janeiro - Fundação Cecierj, e dá Outras Providências. Diário Oficial do Estado do Rio de Janeiro. Rio de Janeiro, RJ, 18 mar. 2002. Disponível em: <http://alerjln1.alerj.rj.gov. br/CONTLEI.NSF/f25edae7e64db53b032564fe005262ef/54bc5c4e096531660 3256b8e005cc9c9?OpenDocument>. Acesso em: 15 dez. 2015.

. Lei $\mathrm{N}^{0} 5.346$, de 11 de dezembro de 2008. Dispõe sobre o novo sistema de cotas para ingresso nas Universidades Estaduais e dá outras providências. Diário Oficial do Estado do Rio de Janeiro. Rio de Janeiro, RJ, 11 dez. 2008. Disponível em: <http://alerjln1.alerj.rj.gov.br/contlei.nsf/c8aa09 00025feef6032564ec0060dfff/1b96527e90c0548083257520005c15df?OpenD ocument>. Acesso em: $17 \mathrm{dez} .2015$.

. Fundação CECIERJ / Consórcio CEDERJ. Rio de Janeiro:

CEDERJ, 2015. Disponível em: <http://cederj.edu.br/cederj/onde-estudar// $>$. Acesso em: 26 nov. 2015.

SALGADO, A. Mão de obra qualificada em polos industriais é tema do Encontros FAPERJ. Rio de Janeiro: FAPERJ, 2015. Disponível em: $<$ http:// www.faperj.br/?id=3040.2.0 . Acesso em: 16 out. 2015.

SARAIVA, L. A. S.; NUNES, A. S. A efetividade de programas sociais de acesso à educação superior: o caso do ProUni. Revista de Administração Pública, v. 45, n. 4, p. 941-964, 2011. doi: http://dx.doi.org/10.1590/S0034-76122011000400003

SEMBAY, M. J. Educação a Distância: bibliotecas de polos de apoio presencial e bibliotecários. 2009. 173 f. Dissertação (Mestrado em Ciência da Informação) - Universidade Federal de Santa Catarina, Florianópolis, 2009. 
UNIVERSIDADE ABERTA DO BRASIL. Estatísticas. 2015. Disponível em: $<$ https://web.archive.org/web/20150916081840/http://www.uab.capes.gov.br/ index.php/sobre-a-uab/estatisticas>. Acesso em: 05 dez. 2015.

VALLADARES, J. S. O et al. Consórcio: estratégia de implementação de políticas públicas em EAD. In: Congresso Internacional de EAD, 13, 2007, Curitiba. Anais... Curitiba: ABED, 2007. p. 1-11.

VIANNA, D. M.; ENNE, O. Acompanhando a trajetória do CECIERJ. In: BORGES, R. M. R.; IMHOFF, A. L.; BARCELLOS, G. B. (Org.). Educação e cultura científica e tecnológica: centros e museus de ciências no Brasil. Porto Alegre: EDIPUCRS, 2012.

\section{Informações dos autores}

Georgia de Souza Assumpção: Mestre em Engenharia de Produção e Sistemas pelo Centro Federal de Educação Tecnológica Celso Suckow da Fonseca (Cefet/RJ). Tecnologista do Instituto Brasileiro de Geografia e Estatística (IBGE). Contato: georgiasa@gmail.com

Alexandre de Carvalho Castro: Doutor em Psicologia Social pela Universidade Estadual do Rio de Janeiro (UERJ). Docente do Programa de Pós-graduação do Centro Federal de Educação Tecnológica Celso Suckow da Fonseca (Cefet/RJ). Contato: o.aken@uol.com.br

Álvaro Chrispino: Doutor em Educação pela Universidade Federal do Rio de Janeiro (UFRJ). Docente do Programa de Pós-graduação do Centro Federal de Educação Tecnológica Celso Suckow da Fonseca (Cefet/RJ). Contato: alvaro.chrispino@gmail.com 